\title{
The model forest networks of Canada and Argentina team up at XIIIth World Forestry Congress to showcase local level indicators work
}

by John E. Hall ${ }^{1}$, Sean Dolter ${ }^{2}$ and Monica Gabay ${ }^{3}$

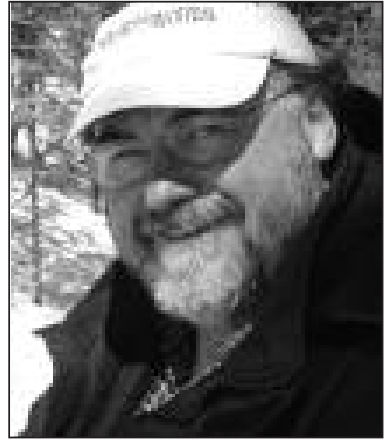

John E. Hall

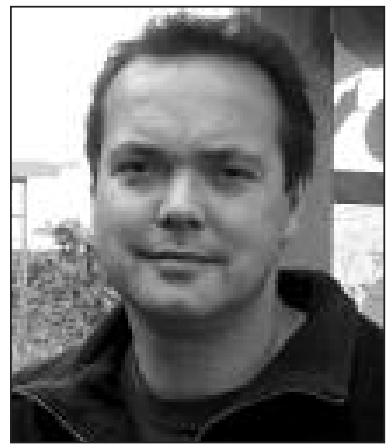

Sean Dolter

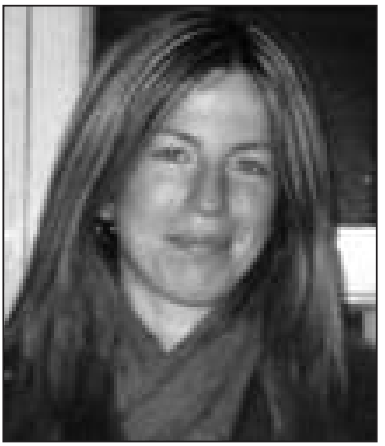

Monica Gabay
For the past 2 years, the Canadian Model Forest Network (CMFN), the Model Forest of Newfoundland and Labrador (MFNL), and Natural Resources Canada - Canadian Forest Service (NRCan-CFS) have been working with the Argentinean Ministry of Environment and Sustainable Development and the Argentina Model Forest Network (AMFN) to help develop local level indicators for sustainable forest management (SFM) that could be applied to Argentinean circumstances. Through annual workshops involving the 6 Argentinean Model Forests, a suite of local level indicators has been developed and is now being tested "on the ground" by the Model Forests. Discussions are underway with the IberoAmerican Model Forest Network to explore expanding the project to other countries in Latin America.

The project will be showcased in a side event at the upcoming World Forestry Congress, being held October 18-25 in Buenos Aires, Argentina. Project collaborators, Dra. Monica Gabay, AMF Program Coordinator, Mr. Sean Dolter, General Manager MFNL and Dr. John Hall, Science Advisor, NRCan-CFS will present the work. A question and answer period will follow.

\section{A Quick Refresher on Criteria and Indicators}

Criteria and Indicators (C\&I) are a framework that logically delineates the topics of sustainable forest management into several parallel streams. Each stream breaks down the chain of characterized topic elements into 4 or 5 significant groupings:

1. Goals

2. Values

3. Indicators

4. Objectives

5. Practices (Optional)

Local Level Indicators (LLI) are a subset of locally measurable data under the "Indicators" grouping of the C\&I framework. LLIs are used as monitoring and reporting measures to judge if SFM is effectively being reached in the defined area.

The LLI framework is incorporated into a management system to help managers to advance and adapt to ever evolving norms by:

- setting the stage for how to gather and integrate information by jurisdiction and time period;

- providing a means of managing a wide range of stakeholder values and expectations

- helping to point the way to improving practice in adaptive management,

- enabling data collection and status reporting to be standardized so that a jurisdiction can track its progress over time and make improvements,

- enable forest certification organizations to track SFM efforts on a defined landbase.

\footnotetext{
${ }^{1}$ Science Advisor, Natural Resources Canada

${ }^{2}$ General Manager, Western Newfoundland and Labrador Model Forest

${ }^{3}$ National Coordinator, Argentina Model Forest Program
} 


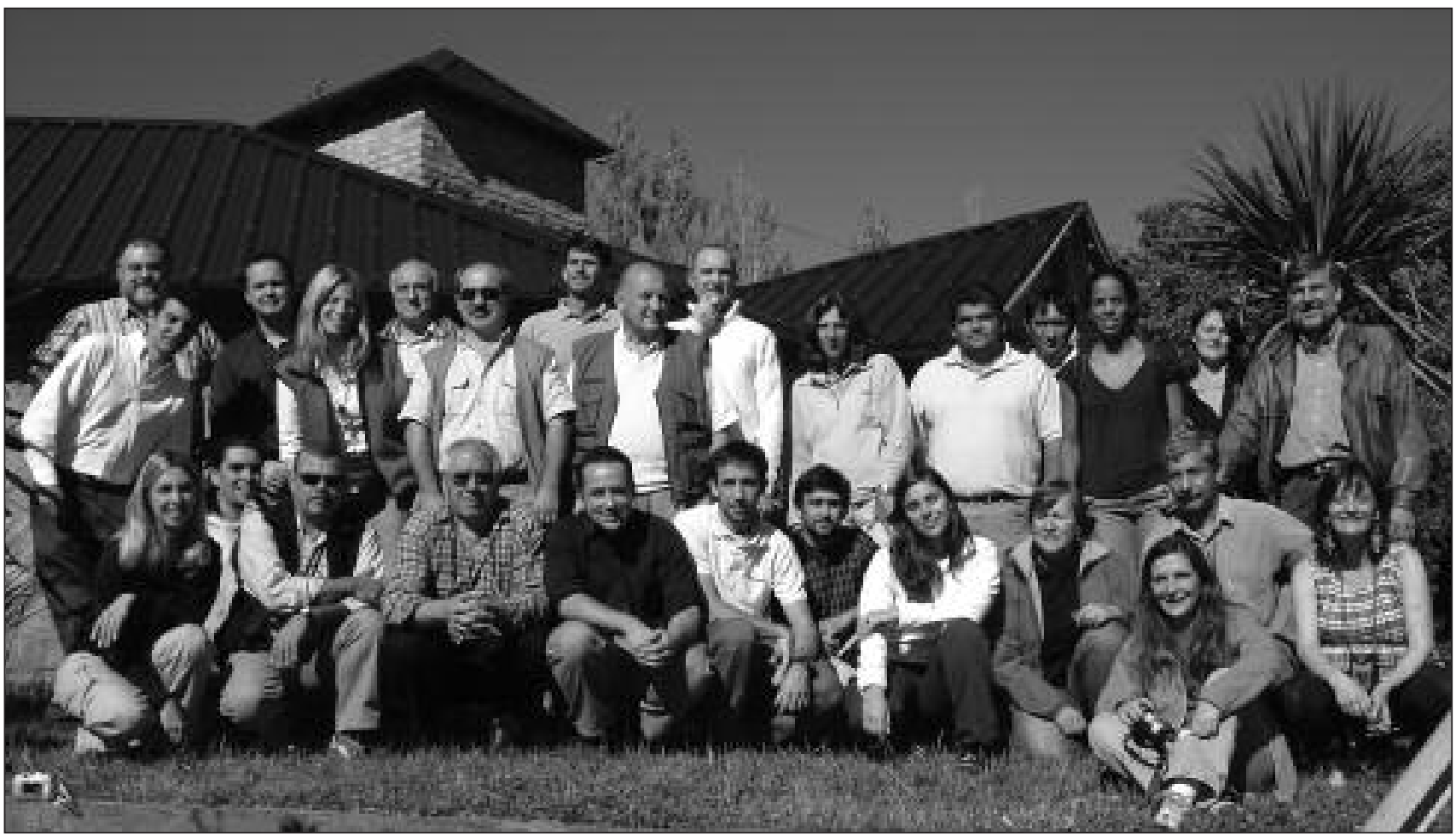

Argentina Model Forest LLI Workshop Participants - March 2008

Uptake of C\&I - examples from Canada: Across Canada, the C\&I framework is being widely adopted and adapted at all levels for the many benefits it offers.

\section{Current examples include:}

National

- National forest strategies - production and evaluation

- State of Forest Reporting - data collection and management

- Links and contributions to other sectors indicator processes

- Research - identifying needs and organizing programs

- International trade support - evidence of commitment to SFM

Provinces and Territories

- Provincial forest strategies

- Forest policies and regulations

- State of Forest Reporting

Local

- Forest Licences:

- Forest management planning

- Forest certification and forest audits

- Model Forests:

- planning tool

- reporting framework for progress to SFM objectives

\section{Quotes}

"Now the AMFN has a strategic plan in place to lead its model forest sites to a unique milestone where all Argentine sites are contributing to the data acquisition and monitoring framework that can be rolled up from the site level to influence management at the national level." - Monica Gabay

"Canada's acknowledged leadership, expertise and experience in C\&I can make a valuable, lasting contribution to SFM in Latin America and across the globe. I'm pleased to be part of this important initiative." - John Hall

"As Model Forests, we are committed to sharing our experiences with our Model Forest colleagues in Argentina and other countries... and vice versa. Our local level indicator experience in Newfoundland and Labrador is the result of hard work involving many partners, most notably the commitment of the Corner Brook Pulp and Paper Company, the local communities and provincial and federal governments. I am pleased that our experience is helping to develop sustainable forest management strategies and practices outside Canada." - Sean Dolter 